\title{
Evaluation of In Vitro Equivalence for Tablets Containing the Poorly Water- Soluble Compound Atorvastatin
}

\author{
Farzana Akter Popy', Irin Dewan' ${ }^{1}$, Most. Nazma Parvin², and \\ S. M. Ashraful Islam ${ }^{1, *}$ \\ ${ }^{1}$ Department of Pharmacy, University of Asia Pacific, Dhanmondi, Dhaka-1209, Bangladesh \\ ${ }^{2}$ Department of Pharmacy, Stamford University Bangladesh, 51 Siddeswari Road, Dhaka-1217, Bangladesh
}

\begin{abstract}
This paper describes the evaluation of the in vitro equivalence of tablets containing a poorly water-soluble compound, atorvastatin, marketed in Bangladesh under biowaiver conditions. Drug release was compared with that of a reference product. The in vitro equivalence test was carried out in three different media $(\mathrm{pH} 1.2, \mathrm{pH} 4.5$, and pH 6.8). Test results were subjected to statistical analysis to compare the dissolution profiles. Model-independent approaches of difference factor $\left(f_{1}\right)$, similarity factor $\left(f_{2}\right)$, and dissolution efficiency $(\% \mathrm{DE})$ were employed. Dissolution profiles of test and reference (innovator) atorvastatin are equivalent at $\mathrm{pH} 6.8$ without statistical treatment. The test products are equivalent at $\mathrm{pH} 4.5\left(f_{1}<15\right.$ and $\left.f_{2}>50\right)$ and not equivalent at $\mathrm{pH} 1.2\left(f_{1}>15\right.$ and $\left.f_{2}<50\right)$. Other general quality parameters of these tablets (e.g., weight variation, crushing strength, friability, and disintegration time) were also determined according to established protocols, and test results were within limit.
\end{abstract}

\section{INTRODUCTION}

S ome drugs that have a good clinical therapeutic effect often show low systemic availability because of poor water solubility. Up to 40 percent of new chemical entities discovered by the pharmaceutical industry today are poorly soluble or lipophilic compounds. The solubility issues complicate the delivery of these new drugs and many existing drugs (1). Poorly water-soluble drugs show unpredictable absorption and high intrasubject and intersubject variability (2-4). Therefore, constant surveillance of marketed, poorly water-soluble drugs by the government, manufacturers, and independent research groups is essential to ensure availability of quality medicines.

Atorvastatin, a synthetic lipid-lowering agent, is an inhibitor of 3-hydroxy-3-methyl-glutaryl-coenzyme A (HMGCoA) reductase, which catalyzes the conversion of $\mathrm{HMG}-\mathrm{Co} A$ to mevalonate, an early rate-limiting step in cholesterol biosynthesis (5). The calcium salt of atorvastatin is currently used for the treatment of hypercholesterolemia (6).

The intestinal permeability of atorvastatin is high at the physiologically relevant intestinal $\mathrm{pH}(7,8)$. However, it has been reported that the absolute bioavailability of atorvastatin is only $12 \%$ after a $40-\mathrm{mg}$ oral dose (9). The low systemic availability is attributed to low dissolution, presystemic clearance in gastrointestinal mucosa, and hepatic first-pass metabolism (10).

Atorvastatin calcium is a crystalline powder and is insoluble in aqueous solution at $\mathrm{pH} 4$ and below. It is very slightly soluble in water. The solubility in aqueous solu-

${ }^{*}$ Corresponding author. tion at $\mathrm{pH} 2.1$ is about $0.0204 \mathrm{mg} / \mathrm{mL}$, while the solubility in $\mathrm{pH} 6.0$ aqueous solution is about $1.23 \mathrm{mg} / \mathrm{mL}$ (11). The dose/ solubility $(\mathrm{D} / \mathrm{S})$ ratio for atorvastatin is greater than $250 \mathrm{~mL}$ for the 10-mg dose at $\mathrm{pH} 1.2$, although the drug dissolves in $250 \mathrm{~mL}$ of buffer solution at $\mathrm{pH} 6.8$. Therefore, atorvastatin is a low solubility drug according to WHO Guidance (12). Atorvastatin is not listed in the WHO Model list and is not classified according to BCS by WHO (13). Because of its solubility (low) and permeability (high), atorvastatin is assigned to BCS Class 2 according to WHO guidance.

We selected atorvastatin tablets to evaluate the quality of locally available, lipid-lowering drugs with special emphasis on the study of disintegration and dissolution properties of the test samples due to their immense importance in predicting drug bioavailability as well as product quality. We used USP buffer solutions of $\mathrm{pH} 1.2$ (hydrochloric acid solution), $\mathrm{pH} 4.5$ (acetate buffer solution), and pH 6.8 (phosphate buffer solution). Six units were tested for dissolution. Other general quality parameters of these tablets like weight variation, crushing strength, friability, disintegration time were also determined according to established protocols. The test results were subjected to statistical analysis to compare the dissolution profile. Model independent approaches of difference factor $\left(f_{1}\right)$, similarity factor $\left(f_{2}\right)$, and dissolution efficiency (\%DE) were employed.

\section{MATERIALS AND METHODS}

\section{Chemicals}

Standard atorvastatin calcium was a kind gift from Incepta Pharmaceuticals Ltd., Bangladesh. Three brands 


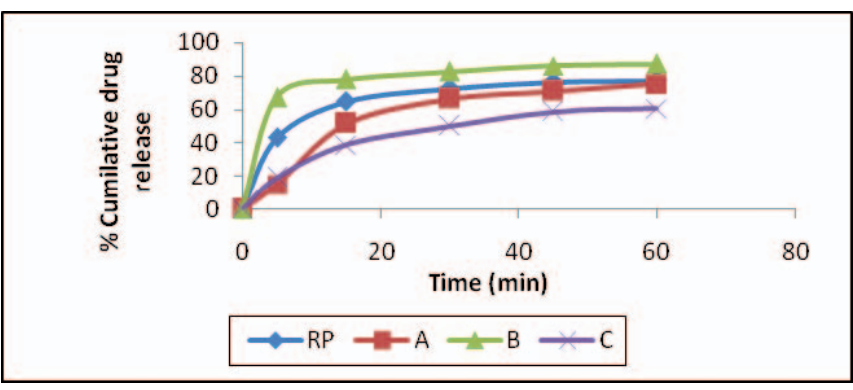

Figure 1.Dissolution profiles of test and reference drugs at pH 1.2.

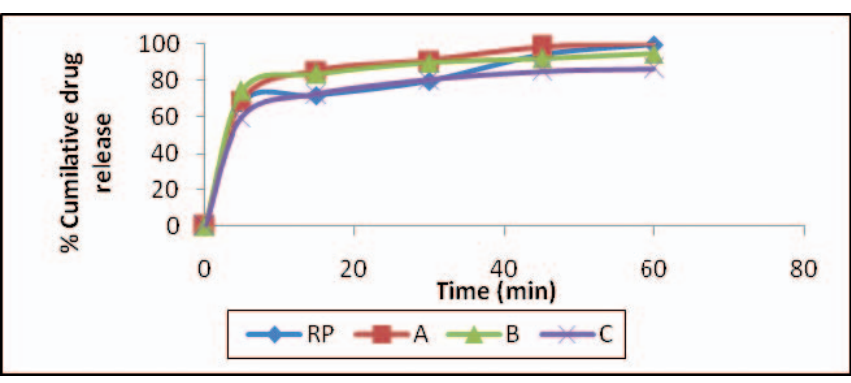

Figure 2. Dissolution profiles of test and reference drugs at pH 4.5.

of generic atorvastatin tablets (10 $\mathrm{mg}$ ) along with the innovator brand (reference product) were purchased from local drug stores in Dhaka city. The samples were properly checked for their manufacturing license numbers, batch numbers, and production and expiry dates. They were randomly coded as A-C and stored properly. Acetonitrile was of HPLC grade. Orthophosphoric acid and other reagents were of analytical reagent grade. Water was deionized and double distilled.

\section{Test of Physicochemical Parameters}

The average weights for each brand as well as the percentage deviation from the mean value were calculated by weighing 20 tablets of each brand with an analytical balance (AY-200, Shimadzu, Japan). The crushing strength was determined with an Automatic Tablet Hardness Tester (8M, Dr. Schleuniger, Switzerland). Twenty tablets of each brand were weighed and subjected to abrasion by employing a Veego friabilator (VFT-2, India) at $25 \mathrm{rev/}$

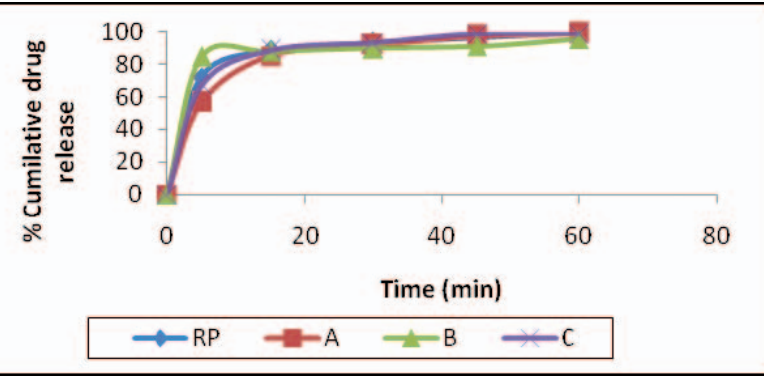

Figure 3. Dissolution profiles of test and reference drugs at $\mathrm{pH} 6.8$.

$\min$ for $4 \mathrm{~min}$. The tablets were then weighed, the weights were compared with the initial weights, and the percentage friability was calculated. Six tablets from each brand were employed for the disintegration test using a Tablet Disintegration Tester (Model: VDT-2, Veego, India). The disintegration time was taken as the time when no particle remained on the basket of the system.

\section{HPLC Analysis}

A Shimadzu HPLC system consisting of two LC-20 AT pumps was used for the quantification of atorvastatin in tablets. The drug analysis data were acquired and processed using LC Solution software (Version 1.2, Shimadzu, Japan) running under Windows XP on a Pentium PC. Here, $0.025 \mathrm{M}$ phosphoric acid ( $\mathrm{pH}$ 2.8)/acetonitrile (30:70) was used as the mobile phase. The flow rate was $1 \mathrm{~mL} / \mathrm{min}$, injection volume was $20 \mu \mathrm{L}$, and UV detection was at 245 $\mathrm{nm}$. The temperature was maintained at ambient $\left(30^{\circ} \mathrm{C}\right)$, and the sensitivity was 0.0005 . The retention time of atorvastatin was $2.75 \mathrm{~min}$.

\section{Dissolution Test}

The dissolution test was undertaken using USP Apparatus 2 (TDT-08L, Electrolab, India) at $75 \mathrm{rpm}$. Dissolution media were USP buffer solutions of $\mathrm{pH} 1.2$ (hydrochloric acid solution), $\mathrm{pH} 4.5$ (acetate buffer solution), and $\mathrm{pH} 6.8$ (phosphate buffer solution). The medium was maintained at $37 \pm 0.5^{\circ} \mathrm{C}$. In all experiments, $5 \mathrm{~mL}$ of dissolution sample was withdrawn at 0, 5, 10, 15, 30, and 45 min and replaced with an equal volume to maintain sink conditions. Samples were filtered and assayed by a validated HPLC method. The concentration of each sample was

Table 1. Values of $f_{1}, f_{2}$, and \%DE for Test and Reference Drugs at $p H 1.2,4.5$, and 6.8

\begin{tabular}{|c|c|c|c|c|c|c|c|c|c|}
\hline \multirow{2}{*}{ Brand } & \multicolumn{3}{|c|}{ pH 1.2} & \multicolumn{3}{|c|}{ pH 4.5} & \multicolumn{3}{|c|}{ pH 6.8} \\
\hline & $f_{2}$ & $f_{1}$ & $\% \mathrm{DE}$ & $f_{2}$ & $f_{1}$ & $\% \mathrm{DE}$ & $f_{2}$ & $f_{1}$ & $\% \mathrm{DE}$ \\
\hline Reference Product & & & 67.16 & & & 79.62 & & & 71.88 \\
\hline$A$ & 39.64 & 20.61 & 56.19 & 52.40 & 8.28 & 88.27 & 54.23 & 8.36 & 68.08 \\
\hline B & 40.58 & 22.17 & 79.86 & 52.40 & 10.72 & 86.73 & 59.20 & 6.68 & 71.71 \\
\hline C & 32.24 & 34.93 & 44.39 & 53.95 & 7.40 & 76.36 & 77.54 & 2.21 & 71.08 \\
\hline
\end{tabular}


determined from a calibration curve obtained from pure samples of atorvastatin.

\section{Data Analysis}

The uniformity of weight was analyzed with simple statistics while the dissolution profiles were analyzed by difference factor $\left(f_{1}\right)$, similarity factor $\left(f_{2}\right)$, and dissolution efficiency $(\% D E)$.

\section{RESULTS AND DISCUSSION}

The tablet weight variation for all the brands was low ( $<3.5 \%$ deviation). Crushing strength of the tablets was in the range $40-75 \mathrm{~N}$, and the percentage weight loss in the friability test was $\leq 0.5 \%$ for all batches. Drug contents of the tablets in all batches were within specification (98-102\%). Overall, the tablets were of good quality with regard to crushing strength, friability, weight uniformity, and drug content.

The results of the dissolution studies are graphically represented in Figures $1-3$. Values for $f_{1}$ and $f_{2}$ were calculated from the dissolution data. The difference factor $f_{1}$ is the percentage difference between two curves at each point and is a measurement of the relative error between the two curves. The similarity factor $\left(f_{2}\right)$ is a logarithmic reciprocal square-root transformation of the sum of squared error and is a measurement of the similarity in the percent dissolution between the two curves. The following equations were used to calculate difference factor $f_{1}$ and similarity factor $f_{2}$

$$
\begin{gathered}
f_{1}=\left\{\left[\sum_{t=1}^{n}\left|R_{t}-T_{t}\right|\right] /\left[\sum_{t=1}^{n} R_{t}\right]\right\} \times 100 \\
f_{2}=50 \cdot \log \left\{\left[1+\frac{1}{n} \sum_{t=1}^{n}\left(R_{t}-T_{t}\right)^{2}\right]^{-0.5} \times 100\right\}
\end{gathered}
$$

where $n$ is the number of time points, $R_{t}$ is the dissolution value of reference product at time $t$, and $T_{t}$ is the dissolution value for the test product at time $t$. Dissolution efficiency (\%DE) is the area under the dissolution curve within a time range $\left(t_{1}-t_{2}\right)$. Table 1 shows the $f_{1}, f_{2}$, and $\% \mathrm{DE}$ values of different brands with respect to the reference product.

Dissolution profiles in $\mathrm{pH} 6.8$ buffer were similar without statistical treatment (percent cumulative release was greater than $85 \%$ within 15 min for test and reference products). For $\mathrm{pH} 4.5$, the similarity factor $f_{2}$ value was greater than 50 , and $f_{1}$ was less than 15 ; therefore, the dissolution profile of the test product is similar to that of the reference product at $\mathrm{pH}$ 4.5. Dissolution profiles in $\mathrm{pH} 1.2$ buffer are considered not similar because the calculated factors do not meet the acceptance criteria $\left(50 \leq f_{2} \leq 100\right.$; $\left.0 \leq f_{1} \leq 15\right)$. Test products may have contained alkalizing agents that possibly increased atorvastatin solubility, which caused the dissolution profile dissimilarity. The addition of alkalizing agents in a formulation significantly increases the solubility of atorvastatin, especially at low $\mathrm{pH}$ (14).

Dissolution efficiency (\%DE) was also employed to compare drug release from various brands. \%DE is the area under the dissolution curve within a time range $\left(t_{1}-t_{2}\right)$ and is defined as

$$
D E=\frac{\int_{t_{1}}^{t_{2}} y \cdot d t}{y_{100} \times\left(t_{2}-t_{1}\right)} \times 100
$$

where $y$ is the percentage of dissolved product. Table 1 shows the dissolution efficiency of different brands. The reference and test products are considered equivalent if the difference between their dissolution efficiencies is within appropriate limits ( $\pm 10 \%$ is often used) (15). Dissolution efficiencies of the test products were almost similar to the reference products in $\mathrm{pH} 4.5$ and 6.8 media. However, test products were not similar to the reference product in $\mathrm{pH} 1.2$ buffer due to the difference between their \%DE values.

\section{CONCLUSION}

The dissolution profiles of the test products were similar to that of the reference product in $\mathrm{pH} 4.5$ and 6.8 buffers, but not similar in $\mathrm{pH} 1.2$ buffer using the paddle method at $75 \mathrm{rpm}$, although test brand $\mathrm{B}$ showed higher drug release at $\mathrm{pH} 1.2$ within the testing time period. However, in vivo testing may be required for final comments regarding the similarity between marketed brands and the reference products.

\section{REFERENCES}

1. Hite, M.; Turner, S.; Federici, C. Part 1: Oral Delivery of Poorly Soluble Drugs. Pharm. Manuf. Packing Sourcer 2003, Summer. http://www.scolr.com/lit/ PMPS_2003_1.pdf (accessed Oct 1, 2012).

2. Goldberg, A. H.; Gibaldi, M.; Kanig, J. L. Increasing dissolution rates and gastrointestinal absorption of drugs via solid solutions and eutectic mixtures I: Theoretical considerations and discussion of the literature. J. Pharm. Sci. 1965, 54 (8), 1145-1148.

3. Goldberg, A. H.; Gibaldi, M.; Kanig, J. L. Increasing dissolution rates and gastrointestinal absorption of drugs via solid solutions and eutectic mixtures II: Experimental evaluation of a eutectic mixture: Ureaacetaminophen system. J. Pharm. Sci. 1966, 55 (5), 482-487.

4. Goldberg, A. H.; Gibaldi, M.; Kanig, J. L.; Mayersohn, $M$. Increasing dissolution rates and gastrointestinal absorption of drugs via solid solutions and eutectic mixtures IV: Chloramphenicol-urea system. J. Pharm. Sci. 1966, 55 (6), 581-583.

5. Lennernäs, H. Clinical pharmacokinetics of atorvastatin. Clin. Pharmacokinet. 2003, 42 (13), 1141-1160.

6. Colhoun, H. M.; Betteridge, D. J.; Durrington, P. N. 
Primary prevention of cardiovascular disease with atorvastatin in type 2 diabetes in the Collaborative Atorvastatin Diabetes Study (CARDS): multicentre randomised placebo-controlled trial. Lancet 2004, 364 (9435), 685-696.

7. Lennernas, H. Human jejunal effective permeability and its correlation with preclinical drug absorption models. J. Pharm. Pharmacol. 1997, 49 (7), 627-638.

8. Wu, X.; Whitfield, L. R.; Stewart, B. H. Atorvastatin Transport in the Caco-2 Cell Model: Contributions of P-Glycoprotein and the Proton-Monocarboxylic Acid Co-Transporter. Pharm. Res. 2000, 17 (2), 209-215.

9. Corsini, A.; Bellosta, S.; Baetta, R.; Fumagalli, R.; Paoletti, R.; Bernini, F. New insights into the pharmacodynamic and pharmacokinetic properties of statins. Pharmacol. Ther. 1999, 84 (3), 413-428.

10. Cilla, D. D.; Whitfield, J. L. R.; Gibson, D. M.; Sedman, A. J.; Posvar, E. L. Multiple-dose pharmacokinetics, pharmacodynamics, and safety of atorvastatin, an inhibitor of HMG-CoA reductase, in healthy subjects. Clin. Pharmacol. Ther. 1996, 60 (6), 687-695.

11. Kearney, A. S.; Crawford, L. F.; Mehta, S. C.; Radebaugh, G.W. The interconversion kinetics, equilibrium, and solubilities of the lactone and hydroxyacid forms of the HMG-CoA reductase inhibitor, Cl-981. Pharm. Res. 1993, 10 (10), 1461-1465.

12. WHO Expert Committee on Specifications for Pharmaceutical Preparations. Proposal to waive in vivo bioequivalence requirements for WHO Model List of Essential Medicines immediate-release, solid oral dosage forms; WHO Technical Report Series, No. 937, Annex 8; World Health Organization: Geneva, Switzerland, 2006.

13. WHO Expert Committee on Specifications for Pharmaceutical Preparations. WHO Model List of Essential Medicines, 15th list; World Health Organization: Geneva, Switzerland, 2007.

14. Ahjel, A. W.; Lupuleasa, D. Enhancement of Solubility and Dissolution Rate of Different forms of Atorvastatin Calcium in Direct Compression Tablet Formulas. Farmacia 2009, 57 (3), 290-300.

15. Anderson, N. H.; Bauer, M.; Boussac, N.; Khan-Malek, R.; Munden, P.; Sardaro, M. An evaluation of fit factors and dissolution efficiency for the comparison of in vitro dissolution profiles. J. Pharm. Biomed. Anal. 1998, 17 (4-5), 811-822. 